\title{
Use of Mixed Methods and Reflection: A Novice Researcher's Perspective
}

\author{
Pragashnie Govender ${ }^{1}$ \\ ${ }^{1}$ Discipline of Occupational Therapy, School of Health Sciences, University of KwaZulu-Natal, South Africa \\ Correspondence: Pragashnie Govender, School of Health Sciences, University of KwaZulu-Natal, South Africa \\ E-mail: naidoopg@ukzn.ac.za
}

Received: February 7, 2019 Accepted: September 30, 2019 Online Published: November 3, 2019

doi:10.5539/gjhs.v11n13p8 URL: https://doi.org/10.5539/gjhs.v11n13p8

\begin{abstract}
Novice researchers are often faced with the challenge of producing rigourous research outputs using a variety of appropriate methods. Often, one is challenged with how decisions are to occur when negotiating the use of mixed methods, which has surged in the last decade. In this paper, the author attempts to share with novice researchers lessons learnt in the use of mixed methods as well as reflection in practice-based research.
\end{abstract}

Keywords: mixed methods, pragmatism, reflection, novice researchers

\section{Getting Started with a Mixed Methods Study: Critical Influences on Decisions in Study Design}

Every researcher has the initial task of posing that central question that will frame his or her study. In studies where one is determined to seek a solution that is practical and scientific, a more pragmatic stance is often appreciated often with the use of mixed methods. In this paper, I intend to unpack some of those initial influences that assisted me as a novice mixed methods researcher in the selection of a relevant design and suitable typology.

Firstly, I found that in beginning this research journey, one needs to acknowledge that research is value-laden and that biases may be present. By being conscious of your own values, attitudes, and biases, you begin to ask essential questions around what type of data needs to be collected, what types of methods would explain or shape the understanding of this question (Hesse-Biber, 2012) and what would be most practical and useful to those who are to consume and benefit from this particular research.

Secondly, as a novice researcher I realised that I had to embed myself in the available literature, especially around the methodology that I had selected. In mixed methods research, given the mounting evidence in the field, I soon realised that exhausting options were not possible. In admission, I found that the design evolved as the study progressed.

Thirdly I acknowledged that research within my field of health sciences often requires the use of both qualitative and quantitative forms of data (Fetters, Curry, \& Creswell, 2013) lending the field suitable to mixed methods research, and was cognisant of the 'exciting heterogeneity' (Hesse-Biber \& Johnson, 2013) that is seen in mixed methods research. So stating my position in this study was a useful starting point. I entered this study as a practitioner and researcher facing real life issues, with a need to answer a clinical question with the best possible available options; a stance that pragmatism seeks to address. Pragmatism is an American philosophy that is derived from the writings of prolific thinkers such as Pierce, James and Dewey as well as Mead, Murphy, Patton and Rorty (Creswell, 2015). A number of authors have argued that pragmatism is the best philosophical partner for mixed methods research. As such, my standpoint was that my research practice will determine what options were possible and not an a priori reasoning or truth by assertion (Johnson \& Onwuegbuzie, 2004). Consequently, methods in my study were selected based on appropriateness to address the questions at hand.

As the fourth step, I considered practical inquiry decisions (Tashakkori \& Teddlie, 2010), such as viewing knowledge as both constructed and as a function of human-environment transactions and by recognising that knowledge is fallible. I thus considered both non-propositional knowledge or tacit knowledge of professionals (Rycroft-Malone, Seers, Titchen, Harvey, Kitson \& McCormack, 2004; Eraut, 1985; Eraut, 2000) in addition to propositional knowledge derived from research and scholarship (Rycroft-Malone et al., 2004). I also realised that my study may incorporate both field research and desk research and embraced the belief that truth can come from experience via a problem solving, action focused inquiry process. I thus considered my role as researcher and 
facilitator to empower the participants in this study towards assuming the roles of both participant and co-researchers in this study (Onwuegbuzie, Frels, Collins, \& Leech, 2013). As part of my reflexive stance, I acknowledged that I occupied a hybrid position (Jootun, McGhee, \& Farland, 2009). I envisioned myself as a researcher who attempted to construct the best systematic research design for this particular study, within time, resource and ethical constraints, whilst being slanted by my position as a practitioner facing dilemmas in the clinical field.

As a fifth step, I reviewed my standpoints in this research process. Within a researcher stance, I acknowledged mixed methods research as an inclusive approach to knowledge generation and legitimization (Freshwater, 2014) whilst appreciating its potential to answer real life questions and considered the level of interaction at different points in the research process and deliberated over how integration would be leveraged (Clark \& Creswell, 2011). The plurality of methodological approaches and philosophical perspectives (Hesse-Biber \& Johnson, 2013), proved challenging as I determined what dilemmas and trade-offs were possible. Within a practitioner stance, I focussed on intent rather than timing and emphasis (Creswell, 2015) in my approach to answering the research question. As a health science practitioner, my discipline lends itself well to engaging in mixed methods research as we are able to cross the QUAN-QUAL divide so to speak. In developing this study, I only later realised that I drew on my past experiences and skill, as suggested by Creswell (2015), although unintentionally, in the design of the study. In what I call my risk-taker stance, I opted for methodological diversity and explored all possible options from delving into areas of action research, design-based research and experimental designs and worked through what may be possible given the ethical and contextual constraints as well as what would contribute to mode two knowledge production (Gibbons, Limoges, Nowotny, Schwartzman, Scott, \& Trow, 1994). Context-driven, problem-focused and interdisciplinary science was important whilst I considered an approach that embraced academic rigour and practical relevance.

\section{How the Process of Reflection Was Used in a Pragmatic Study}

Together with gaining insights on how mixed methods could be used in my quest towards answering my question, I found that reflection in the research process was often not adequately interrogated nor exhausted. I drew on the work of a number of authors (Schön, 1987; Alvesson \& Skoldberg, 2009; Killion \& Todnem, 1991; Atkins \& Murphy, 1993; Eraut \& Schön, 1995; Usher, Bryant, \& Johnston, 1997) when considering the processes of reflection in my study. There are a number of different uses of reflection which draws attention to the complex relationship between processes of knowledge production and the involvement of the knowledge producer(Atkins \& Murphy, 1993).

Reflective research has two basic characteristics, that is, careful interpretation and reflection (Atkins \& Murphy, 1993). The former implies that all references to empirical data are the results of interpretation. The latter, turns attention inwards towards the researcher, the relevant research community, society as well as the problematic nature of language and narrative in the research context. Alvesson and Sköldberg (2009) further postulate that methodical reflection on numerous levels can add quality to the interpretation which makes empirical research of value. Schön's perspective is one that emphasises practitioner-generated, intuitive knowledge derived from experience (Schön, 1983; Schön, 1987; Killion \& Todnem, 1991; Atkins \& Murphy, 1993). Thus Schön's concepts of "reflection-in-action" and "reflection-on-action" were used in this study in addition to "reflection-for-action"which Killion and Todnem (1991) extended of Schön's work. These three reflective directions formed the overarching process of reflective practice used in my study. The former two were embedded within the study design with the latter being realised at the end of the study.

There has been criticism with respect to Schön's concepts with the distinction between reflection-in-action and reflection-on-action being debated as Schön appears to have failed to clarify what is involved in the reflective process (Usher et al., 1997). Moreover there has been the absence of psychological realities of reflection-in-action (Munby \& Russell, 1989) as well as the issue around the extent to which Schön does not explore the situated-ness of the practitioner (Bryman, 2006). Given these limitations in the literature, as researcher, I experienced difficulty in practically realising how these processes would work, therefore I was explicit about how I enacted this reflective practice. In reflection-in-action, the individual reflects while carrying out a task. As researcher in this study whilst remaining a practitioner in the field, I found this process useful in describing certain stages of the study especially where knowledge transfer and knowledge brokerage occurred.

A key competency in providing health care in any setting is the ability to be able to appraise relevant research and apply that evidence into practice. I found that this "action" and "decision making" at the time was essential in a move towards evidenced-based practice as well as in realising that research should "come alive" to the consumers of the process. Moreover, the clarity that was required in these processes served to address points of contention that 
were able to be clarified at the time with evidenced-based literature and aided in a more focussed discussion on the areas that were not found to be clear with a lack of evidence. A process of reflection-on-action ensued within a maximum of 24 hours following the experience and was recorded as analytical memos and reflective annotations. Reflection-on-action was also observed followed each data collection stage, in which I attempted to draw on the preceding phases and findings. Within my pragmatic stance, I considered the new information and theoretical perspectives, prior to entering the the next phases of the study.

Reflection-for-action which speaks to a review of what has been accomplished and a process of identifying constructive guidelines to follow in order to show success of the task was also considered. This process assisted me in identifying the need for additional steps in the research process and in assisting towards drawing conclusions for the study and in mapping a way forward.

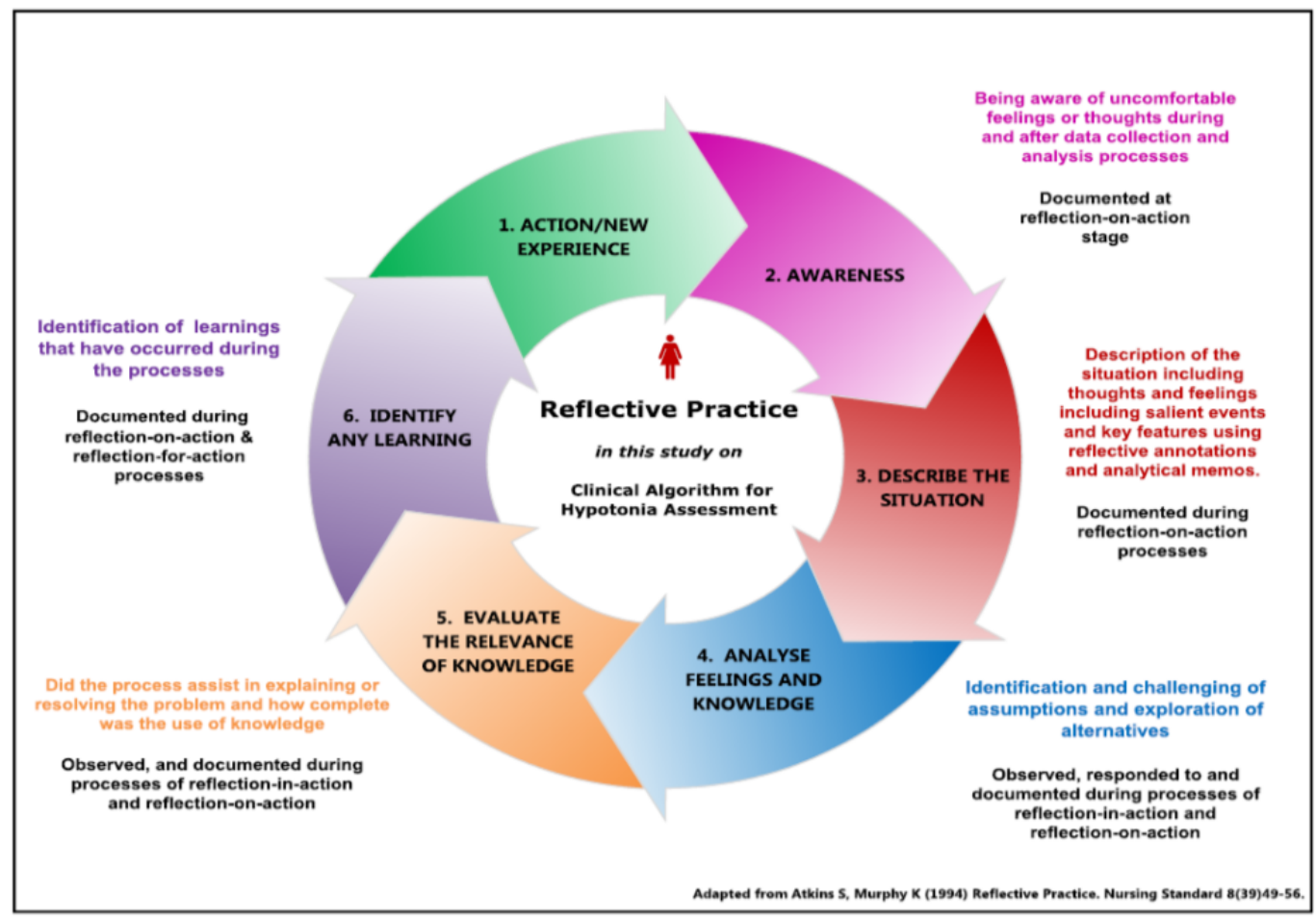

Figure 2. Reflective practice within the study

\section{Negotiated issues around Integration}

The value of mixed methods research is said to be enhanced by how different forms of data are integrated (Bryman, 2006, Fetters et al., 2013; Clark \& Creswell, 2011) and is integral to mixed methods research. In embracing the challenge posed by current leaders in the field of mixed methods research that is, "coming to things differently" (Hesse-Biber \& Johnson, 2013) and in somewhat deliberation over the $1+1=3$ integration formula proposed by Fetters and Freshwater (2015), I considered the level of integration at the design, methods, and reporting levels (Fetters et al., 2013).

\section{Quality Inference}

A research endeavour is often successful when combined with the use of the most suitable research methods in answering the research questions. A number of opportunities exist for the mixed methods researcher. By utilising mixed methods within the same framework, I was able to incorporate the strengths of both methodologies. Quality inference relates to drawing conclusions from the research data and begins during data collection whereby the researcher begins to formulate ideas about the data which is transported and developed through the analysis process (Teddlie \& Tashakkori, 2009). Quality inference speaks to both the quantitative phase in terms of validity internal, statistical and conclusion validity), reliability and generalisability, and the qualitative phase in terms of credibility, trustworthiness, reliability and transferability (Teddlie \& Tashakkori, 2009; Graneheim \& Lundman, 2004). In an attempt to evaluate the quality in this study, I combined the quality issues found in mixed methods 
studies within an integrative framework for mixed methods studies (Hesse-Biber \& Johnson, 2013; Teddlie \& Tashakkori, 2009) in order to more adequately demonstrate processes that were in place to ensure this level of quality in the study.

\section{Lessons for a Novice Mixed Methods Researcher}

As a novice researcher, the following lessons were gained in this research process. I found that there was a sense of leniency in choice of methods in order to answer the clinical question, with a number of possibilities being available towards realising the outputs in my study. Mixed methods offered me an opportunity to work within the resource, contextual and ethical constraints that were posed. I found that the study design emerged following an initial basic typology of an explorative sequential design, with innovation being required in how data was to be integrated. The challenge for a novice researcher like myself, was the need to wade through the literature and developments and to remain current in ensuring what would be considered best practice. Some trade-offs had to negotiated whilst defending the rigour of the research. I found that the many authors provide viewpoints that encourage debate, but I realised that a novice researcher would also have to develop their own candid set of rules in the application of mixed methods to their own study based on their current reading and engagement with the literature. During the process of this study, I realised that new and emerging thoughts around mixed methods research was being published and negotiated this as the study progressed, whilst ensuring authenticity in the research process. The issue around quality inference and what it means in mixed methods research is essential as the term is vaguely used in discipline specific literature, hence the need arose for me as researcher to defend methodological choices and strategies, and forced me to look at the study holistically, as well as sequentially as to what was occurring in each of the various stages. My philosophical position and understanding of pragmatism was also a challenge as the term and concept is still being defined in the literature from different schools of thought (Morgan, 2014). Hence, positioning oneself philosophically in the research was also essential as choices could then be well defended. As a mixed methods researcher, the opportunities appear endless, and in embracing Fetters (2016) analogy, as mixed methods transforming from a horseless carriage to a modern automobile, only in driving (experiencing mixed methods research), can one become a more experienced driver, and learn how to negotiate the bends and curves (philosophical position, integration, quality inference) with this modern automobile.

\section{Acknowledgements}

The author acknowledges Prof. A. J. Onwuegbuzie (Sam Houston State University, Texas, USA) for his critical dialogue around use of mixed methods research.

\section{Competing Interests Statement}

The authors declare that there are no competing or potential conflicts of interest.

\section{References}

Alvesson, M., \& Sköldberg, K. (2009). Reflexive methodology: New vistas for qualitative research. Thousand Oaks, California: SAGE Publications.

Atkins, S., \& Murphy, K. (1993). Reflection: a review of the literature. Journal of advanced nursing, 18(8), 1188-1192. https://doi.org/10.1046/j.1365-2648.1993.18081188.x

Bryman, A. (2006). Integrating quantitative and qualitative research: how is it done?. Qualitative research, 6(1), 97-113. https://doi.org/10.1177/1468794106058877

Creswell, J. W., \& Clark, V. L. P. (2017). Designing and conducting mixed methods research. Sage publications.

Creswell, J. W. (2014). A concise introduction to mixed methods research. SAGE publications.

Eraut, M. (1985). Knowledge creation and knowledge use in professioal contexts. Studies in Higher education, 10(2), 117-133. https://doi.org/10.1080/03075078512331378549

Eraut, M., \& Schön D. (1995). Shock: a case for refraining reflection in action?. Teachers and Teaching: theory and practice, 11, 9-22. https://doi.org/10.1080/1354060950010102

Eraut, M. (2000). Non-formal learning and tacit knowledge in professional work. British journal of educational psychology, 70(1), 113-136. https://doi.org/10.1348/000709900158001

Fetters, M. D., Curry, L. A., \& Creswell, J. W. (2013). Achieving integration in mixed methods designs - principles and practices. Health services research, 48(6pt2), 2134-2156. https://doi.org/10.1111/1475-6773.12117

Fetters, M. D., \& Freshwater, D. (2015). The 1+ 1= 3 Integration Challenge. Journal of Mixed Methods Research, 
9, 115-117. https://doi.org/10.1177/1558689815581222

Fetters, M. D. (2016). “Haven’t We Always Been Doing Mixed Methods Research?” Lessons Learned From the Development of the Horseless Carriage. Journal of Mixed Methods Research, 10, 3-11. https://doi.org/10.1177/1558689815620883

Freshwater, D. (2014). What Counts in Mixed Methods Research Algorithmic Thinking or Inclusive Leadership? Journal of Mixed Methods Research, 8, 327-329. https://doi.org/10.1177/1558689814553092

Gibbons, M., Limoges, C., Nowotny, H., Schwartzman, S., Scott, P., \& Trow, M. (1994). The new production of knowledge: The dynamics of science and research in contemporary societies. Thousand Oaks, California: SAGE Publications.

Graneheim, U. H., \& Lundman, B. (2004). Qualitative content analysis in nursing research: concepts, procedures and measures to achieve trustworthiness. Nurse education today, 24(2), 105-112. https://doi.org/10.1016/j.nedt.2003.10.001

Hesse-Biber, S. (2012). Feminist approaches to triangulation: Uncovering subjugated knowledge and fostering social change in mixed methods research. Journal of Mixed Methods Research, 6(2), 137-146. https://doi.org/10.1177/1558689812437184

Hesse-Biber, S., \& Johnson, R. B. (2013). Coming at things differently: Future directions of possible engagement with mixed methods research. Journal of Mixed Methods Research, 7, 103-109. https://doi.org/10.1177/1558689813483987

Johnson, R. B., \& Onwuegbuzie, A. J. (2004). Mixed methods research: A research paradigm whose time has come. Educational researcher, 33(7), 14-26. https://doi.org/10.3102/0013189X033007014

Jootun, D., McGhee, G., \& Marland, G. R. (2009). Reflexivity: promoting rigour in qualitative research. Nursing Standard (through 2013), 23(23), 42. https://doi.org/10.7748/ns2009.02.23.23.42.c6800

Killion, J. P., \& Todnem, G. R. (1991). A process for personal theory building. Educational leadership, 48(6), 14-16.

Morgan, D. L. (2014). Pragmatism as a paradigm for social research. Qualitative Inquiry, 20(8), 1045-1053. https://doi.org/10.1177/1077800413513733

Munby, H., \& Russell, T. (1989). Educating the reflective teacher: An essay review of two books by Donald Schon. Journal of Curriculum Studies, 21(1), 71-80. https://doi.org/10.1080/0022027890210106

Onwuegbuzie, A. J., Frels, R. K., Collins, K. M., \& Leech, N. L. (2013). Conclusion: A four-phase model for teaching and learning mixed research. International Journal of Multiple Research Approaches, 7(1), 133-156. https://doi.org/10.5172/mra.2013.7.1.133

Rycroft-Malone, J., Seers, K., Titchen, A., Harvey, G., Kitson, A., \& McCormack, B. (2004). What counts as evidence in evidence-based practice?. Journal of advanced nursing, 47(1), 81-90. https://doi.org/10.1111/j.1365-2648.2004.03068.x

Schön, D. (1983). The reflective practitioner: How professionals think in action. New York: Basic Books.

Schön, D. (1987). Educating the reflective practitioner. San Francisco: Jossey Bass.

Tashakkori, A., \& Teddlie, C. (2010). SAGE Handbook of Mixed Methods in Social \& Behavioral Research. Thousand Oaks, California: SAGE Publications. https://doi.org/10.4135/9781506335193

Teddlie, C., \& Tashakkori, A. (2009). Foundations of mixed methods research: Integrating quantitative and qualitative approaches in the social and behavioral sciences. Thousand Oaks, California: Sage.

Usher, R., Bryant, I., \& Johnston, R. (1997). Adult Education and the Postmodern Challenge. Learning beyond the Limits. Routledge, 7625 Empire Drive, Florence, KY 41042.

\section{Copyrights}

Copyright for this article is retained by the author(s), with first publication rights granted to the journal.

This is an open-access article distributed under the terms and conditions of the Creative Commons Attribution license (http://creativecommons.org/licenses/by/4.0/). 